\title{
OPORTUNIDADES DE IMPLEMENTAÇÃO DE CONCEITOS E FERRAMENTAS DE PRODUÇÃO ENXUTA VISANDO MELHORIA DA COMPETITIVIDADE DE EMPRESAS DO APL CALÇADISTA DE JAÚ/SP
}

\author{
OPPORTUNITIES FOR IMPLEMENTATION OF CONCEPTS AND TOOLS LEAN \\ PRODUCTION AIMING TO IMPROVE COMPETITIVENESS OF ENTERPRISES OF SHOE \\ APL JAÚ / SP \\ Célio Favoni* E-mail: favoni@hotmail.com \\ Lillian do Nascimento Gambi** E-mail: Igambi@sc.usp.br \\ Catarina Barbosa Careta** E-mail: catarinacaretta@yahoo.com.br \\ ${ }^{*}$ Faculdade de Tecnologia de Jahu - FATEC JAHU, Jaú, SP \\ ** Escola de Engenharia de São Carlos - USP, São Carlos, SP
}

Resumo: A Produção Enxuta baseia-se em esforços para a eliminação de desperdícios e em atividades que não agregam valor ao consumidor e que possam ser otimizados ou eliminados através da aplicação de conceitos e ferramentas. Considerando que no mundo globalizado a competitividade tem sido cada vez maior, o uso de conceitos e ferramentas, como as da Produção Enxuta, que diminuem os desperdícios no fluxo de valor das empresas, são fundamentais para a melhoria da competitividade e à sobrevivência no mercado. Para as Pequenas e Médias Empresas essa realidade é ainda pior, pois, muitas vezes, devido à carência de recursos financeiros e humanos, elas não conseguem investir em iniciativas de melhoria, como a implementação de conceitos e ferramentas da Produção Enxuta. Esse estudo tem o objetivo de conhecer a realidade de empresas do Arranjo Produtivo Local (APL) de calçados femininos de Jaú/SP e suas práticas de produção, buscando identificar oportunidades de melhoria dentro do contexto teórico pesquisado. Para isso foram realizados estudos de casos em três empresas do APL, e os resultados mostraram que os desafios são comuns às empresas como, por exemplo, a redução de desperdícios, necessidade de melhorias no fluxo de informação, além do pouco conhecimento sobre a Produção Enxuta. Observou-se ainda a oportunidade de aplicação imediata de algumas ferramentas que podem contribuir para melhorias nas empresas estudadas.

Palavras-chave: Produção Enxuta. Arranjo Produtivo Local. Iniciativas de Melhorias. Calçados. Competitividade.

Abstract: Lean production has been applied by organizations around the world as part of strategy to reduce waste in their value stream intending to improve performance. Despite the use of lean production concepts and tools have continually been introduced in different companies, the literature shows the most of application is identified in large companies than in Small-and Medium-sized Enterprises (SMEs). The reason can be the lack of financial and human resources available to the lean initiatives in these enterprises. However, a wide range of concepts and techniques of lean production can be applied without considerable financial investments. This paper aims to study the opportunities and difficulties of lean production applicability in SMEs. Case research was developed in three SMEs of industrial cluster of Jaú/SP and the results suggest that these companies face similar difficulties. Nevertheless, the study confirms that there are several opportunities to implement lean production concepts and techniques which can lead to improve performance in these companies 
Keywords: Lean production. Local Productive Arrangement. improvement initiatives. Shoes. Competitiveness.

\section{INTRODUÇÃO}

A competição global, as rápidas mudanças tecnológicas e o ciclo de vida dos produtos cada vez menor têm orientado as empresas a adotarem novas formas de produção que contribuam para seu sucesso sustentável (DIGALWAR; SANGWAN, 2007; SHAH; WARD, 2003).

A proposta da Produção Enxuta (Lean Production) adotada pelas empresas japonesas a partir dos anos 40 , propiciaram e incluíram novos mecanismos para a excelência de produção, reunindo para tal o melhor dos métodos artesanais e da produção em massa: redução de custos unitários, melhoria da qualidade, mix de produtos e trabalhadores multifuncionais (WOMACK et al., 2004).

O despertar desses novos conceitos somente foi apresentado ao ocidente no final dos anos 80, em razão do lançamento do livro "A máquina que mudou o mundo" de Womack e Jones (1992). Nesse livro foram publicados os resultados de uma pesquisa realizada pelo Massachusetts Institute of Technology (MIT), acerca do desempenho superior das empresas automotivas japonesas, mais especificamente da Toyota Motor Company, frente às empresas americanas.

O Sistema Toyota de Produção (STP) foi criado a partir da identificação dos desperdícios pertinentes à produção e da criação de uma série de ferramentas para evitá-los, partindo de técnicas simples de gestão visual que permitem que cada pessoa saiba o que deve fazer em diferentes situações (HOLWEG, 2007).

$\mathrm{Na}$ literatura tem-se diagnosticado que a implementação, total ou parcial, de conceitos e ferramentas da Produção Enxuta, como: Mapa do Fluxo de Valor (MFV), Trabalho Padronizado, Manutenção Produtiva Total (TPM), Troca Rápida de Ferramentas (SMED), Qualidade Total (TQM), Fluxo Contínuo, Sistemas Puxados, Cadeia de Fornecedores, Kaizen, Gestão Visual, Nivelamento e Balanceamento da Produção e Flexibilização da mão de obra, proporcionam ganhos de competitividade para as empresas, com foco na redução de desperdícios e perdas (NOGUEIRA, SAURIN, 2008). Além disso, tais práticas produzem melhoria tanto ao desempenho 
operacional quanto ao desempenho do negócio (HOFER; EROGLU; HOFER, 2012; KAYNAK, 2003; LIN; CHANG, 2006; SILVA et al., 2010).

Assim, considera-se que há um aumento do interesse em conceitos e ferramentas da Produção Enxuta (SAURIN et al., 2010), e que as Pequenas e Médias Empresas (PMEs), em especial as que produzem calçados, ainda utilizam ultrapassados mecanismos de controle e execução da produção, não contando, portanto, com um foco estratégico (BACHEGA; GODINHO FILHO, 2011).

Mediante a importância dessas empresas para a economia dos municípios, o objetivo deste trabalho é conhecer a realidade das empresas calçadistas do Arranjo Produtivo Local (APL) de Jaú/SP e suas práticas de produção, identificando semelhanças entre elas, os desafios referentes à implementação dos conceitos e ferramentas da Produção Enxuta, bem como as oportunidades de utilização de alguns desses conceitos e ferramentas nas empresas.

A fim de se cumprirem os objetivos propostos, foi efetuado um levantamento bibliográfico sobre a aplicação da Produção Enxuta e Arranjos Produtivos Locais, contando com uma breve caracterização do APL de Jaú. Em seguida, foram realizados estudos de casos em empresas pertencentes a este aglomerado.

\section{FUNDAMENTAÇÃO TEÓRICA}

Apresenta-se nesta seção a síntese de conceitos sobre Produção Enxuta e Arranjos Produtivos Locais que orientam a presente pesquisa.

\subsection{0 modelo fordista de produção}

Após a I Guerra Mundial, Alfred Sloan, da General Motors, e Henry Ford conduziram o sistema de fabricação mundial, que por séculos se deu pela produção artesanal, para uma era de produção em massa ${ }^{1}$, tornando os Estados Unidos na maior economia global do século XX (WOMACK et al., 2004).

\footnotetext{
${ }^{1}$ Produção em massa é a produção em grandes quantidades de produtos padronizados na linha de produção. Este termo foi popularizado por Ford no início do século 20 , com o seu famoso Ford
} 
$\mathrm{Na}$ produção artesanal, os trabalhadores eram altamente qualificados e utilizavam ferramentas simples, mas flexíveis, além de que podiam produzir o que o consumidor desejasse. Neste sistema, o trabalhador fica no mesmo local, se utiliza de diversas ferramentas por várias vezes e praticamente realiza todas as operações. Desta maneira, o produto final é dispendioso para o consumo, tornando sua aquisição inviável para a maioria da população, de maneira que satisfaz apenas uma pequena parcela dos consumidores.

Já na produção em massa, procura-se dividir as tarefas da forma mais simples possível, direcionando-as para um trabalhador que não precisa ser qualificado, ao passo que este realizará a tarefa recebida repetindo-a inúmeras vezes, utilizando, para tanto, máquinas dispendiosas e especializadas em uma única tarefa, geralmente uma mesma ferramenta. Facilita-se neste processo a compra de grandes lotes de materiais, reduzindo assim o custo das despesas como transporte, negociações de compra, etc (WOMACK et al., 2004).

A ideia inicial do sistema de produção fordista, ou produção em massa, era a criação de peças intercambiáveis que não precisassem de ajustes, tornando a linha de montagem mais simples e rápida. Soma-se a isto a capacidade de divisão do trabalho, aumentando a produtividade da mão de obra e reduzindo consideravelmente o custo de produção. A mão de obra não precisava ser especializada e, portanto, eram contratados indivíduos sem nenhuma formação técnica, pois o trabalho era repetitivo e simples. São características desse modelo o longo ciclo do produto e a pouca diversidade ${ }^{2}$, contribuindo ainda o foco no preço, a pouca atenção à qualidade com altos volumes de produção e o ganho focado na economia de escala (HOLWEG, 2007).

Esse modo de produção ajudou os EUA a se firmarem como a maior potência mundial no mundo pós II Guerra, tornando-o um modelo de sociedade industrial capitalista. A era do automóvel, que já prevalecia na América do Norte depois da guerra, atingiu a Europa e logo após, de forma menos intensa, o mundo socialista e aos países latino-americanos. Um dos fatores que colaborava para o espantoso

modelo T. O modelo T de 1908 foi o vigésimo projeto da Ford, começando o projeto inicial com o modelo A, em 1903 (WOMACK et al, 2004).

${ }^{2}$ No início da década de 1920, Ford atingiu o pico de produção de 2 milhões de veículos iguais, e havia cortado mais de $2 / 3$ do custo real para o consumidor (WOMACK et al., 2004). 
sucesso da indústria automobilística era o baixo preço dos combustíveis ${ }^{3}$. Estima-se que na Itália existiam cerca de 750 mil automóveis em 1938, saltando para 15 milhões em 1975 (HOBSBAWN, 2003).

O modelo de produção em massa que ajudou o boom de crescimento econômico no mundo pós-guerra, também se espalhou para outros setores, como o da construção de casas, a chamada junk food, sendo o McDonald's a história de maior sucesso (HOBSBAWN, 2003).

A história poderia ter prosseguido no modo americano de produção mediante as seguintes circunstâncias: se os preços dos combustíveis não tivessem aumentado drasticamente a partir dos anos 1970; se os consumidores não passassem a exigir modelos com algum diferencial (ar condicionado, som stereo, etc); se não tivesse emergido uma nova indústria automobilística no Japão (WOMACK et al., 2004). Nesse sentido, a competição passou a ser por preço, qualidade e design (YOSHINO, 2008).

\subsection{Produção Enxuta}

Diversos estudos têm demonstrado que o sistema de produção introduzido pela Toyota, a Produção Enxuta ou Lean Production, é o sucessor do tradicional modelo de produção em massa fordista, podendo esse novo modelo ser aplicado em qualquer organização empresarial (PETTERSEN, 2009; SHAH; WARD, 2003; SHINGO, 1996), e que o crescimento da aplicação desta filosofia nas organizações ocorreu devido à validação de seus resultados, sendo o tema de várias pesquisas (ANTONY, 2011; FULLERTON; MCWATTERS, 2001; HALLGREN; OLHAGER, 2009; KAYNAK, 2003; SALGADO et al, 2009).

A Toyota chamou a atenção mundial quando a qualidade e a eficiência dos carros japoneses superaram os produzidos no ocidente, sobretudo porque duravam mais que os carros americanos e exigiam menor manutenção (LIKER, 2005).

A história da Toyota se confunde com a própria história do Japão. Nos anos presentes na década de 50 do século $\mathrm{XX}$, o governo japonês acreditava que uma

\footnotetext{
${ }^{3}$ Durante o período entre 1950 e 1973, o preço do petróleo saudita era comercializado por menos de dois dólares o barril (HOBSBAWN, 2003).
}

Revista Produção Online, Florianópolis, SC, v.13, n. 3, p. 1118-1142, jul./set. 2013. 
indústria automobilística forte deveria ser de produção elevada, com especialização em diferentes tamanhos de carros e preços competitivos. Em vez disso, a Toyota, a Nissan e outras companhias desafiaram o governo e se propuseram a serem os construtores de carros completos e com variedade de modelos. O principal engenheiro da Toyota e, responsável pela implantação de novas formas de produção, Taiichi Ohno, rapidamente percebeu que utilizar os métodos norteamericanos de produção, ou ainda a produção artesanal, não atenderia as necessidades japonesas de mercado e da indústria. Diante disso, teve que ser procurado um novo enfoque de produção (WOMACK et al., 2004).

Por volta de 1940, a companhia comprou prensas americanas para a fabricação de automóveis. Devido ao tamanho do mercado japonês, essas prensas tinham que operar com relativa flexibilidade, ou seja, fabricava-se de acordo com a mudança de desenho do produto. Essa maneira de produzir em pequena escala, obrigou-os a criar trocas rápidas de sua ferramentaria (setup), e assim tornarem as máquinas e consequentemente a produção, flexíveis. No início, a Toyota importou máquinas, mas com a guerra, a empresa solidificou seu sistema produtivo com máquinas e equipamentos próprios, o que a tornou independente em máquinas "chão de fábrica", e a fez reduzir seu custo em torno de $12 \%$ por unidade manufaturada (HOUNSHELL, 1984).

Diante da impossibilidade de ser implantada a filosofia de produção americana, Taiichi Ohno acreditava na importância do fluxo contínuo de materiais, na padronização dos processos e na eliminação de perdas (desperdícios), diferentemente do que acontecia no Fordismo.

A abordagem Just in Time (JIT) foi uma contribuição de Kiichiro Toyoda, (fundador da Toyota Motor Company), influenciado por uma viagem de estudo às plantas da Ford em Michigan, Estados Unidos, em que conheceu o sistema de supermercado, que recoloca os produtos nas prateleiras assim que os clientes os compram (LIKER, 2005). Dessa visão surgiu o sistema Kanban, que foi implementado em 1950, por meio de Taiichi Ohno, e originalmente chamado de "sistema de supermercado", adaptando-se ao processo fabril da Toyota (FUJIMOTO; TIDD, 1984).

Revista Produção Online, Florianópolis, SC, v.13, n. 3, p. 1118-1142, jul./set. 2013. 
Em 1946, Ohno propôs algumas ferramentas que passariam a ser utilizadas no Sistema Toyota de Produção (STP), tais como: nivelamento do volume de produção; JIT (Kanban); layout focado no produto; trabalho multifuncional, bem como a padronização do trabalho. Para o nivelamento da demanda, criou-se o Heijunka Box, a fim de nivelar a produção na montagem e na manufatura (HOLWEG, 2007).

De acordo com Liker (2005), a Toyota identificou sete grandes tipos de perdas (muda) sem agregação de valor em processos administrativos ou de produção:

- Superprodução: produção de itens para os quais não existe consumo, o que exige custos de estoques, transporte e excesso de pessoal;

- Espera (tempo sem trabalho): funcionários que ficam vigiando uma máquina ou esperam pelo próximo passo no processamento;

- Transporte ou movimentação desnecessária: movimento de estoque em processo por longas distâncias, criação de transportes ineficientes ou movimentação de materiais para dentro ou fora do estoque ou entre processos;

- Superprocessamento ou processamento incorreto: passos desnecessários para processar peças. Uso de ferramenta de baixa qualidade, causando movimentos desnecessários e produzindo defeitos;

- Excesso de estoques: excesso de matéria-prima, de estoque em processo (WIP-Work in Process) ou de produtos acabados;

- Movimento desnecessário: qualquer movimento inútil que os funcionários têm que fazer durante o trabalho;

- Defeitos: produção de peças defeituosas ou para correção. Incluem também, perdas relacionadas com retrabalho, descarte ou inspeção.

Dentro da filosofia da Produção Enxuta, um dos principais conceitos é o kaizen, isto é, uma abordagem de melhoria contínua para eliminar desperdícios, sendo que o princípio é melhorar o trabalho em toda a sua organização, focando nas operações que não agregam valor para eliminar desperdícios que geram custos e não valorizam o produto ou serviço (YOSHINO, 2008). 
A Produção Enxuta, às vezes referida como Just-in-Time, também se refere a outros conceitos e ferramentas: fluxo contínuo de materiais, produção puxada, 5S, poka yokes, trabalho padronizado, controle visual, entre outros, usados para favorecer o lucro a curto, médio e longo prazo, e a possibilidade de fazer mais com os mesmos recursos (DEMETER; MATYUSZ, 2011; MACKELPRANG; NAIR, 2010; PETTERSEN, 2009).

Para identificar desperdícios, uma ferramenta da Produção Enxuta indispensável é o Mapeamento do Fluxo de Valor, ou Value Stream Mapping (VSM), em que se pode visualizar os processos produtivos, representado pelos fluxos de materiais e informações (RAHMAN; LAOSIRIHONGTHONG; SOHAL, 2010; RENTES et al., 2003; ROTHER; SHOOK, 2003).

Segundo autores como Womack e Jones (2004), Saurin, Marodin e Ribeiro (2011) e Thomas et al. (2012), a Produção Enxuta é uma forma de especificar valor, alinhando-o a melhor sequência de acordo com o que agrega valor para o cliente final, contando com menos esforço humano, menor quantidade de equipamento e estoque reduzido em curto espaço de tempo.

\subsection{Arranjo Produtivo Local e Indústrias de Calçados}

Arranjos Produtivos Locais (APLs) ou Sistemas Locais de Produção (SLP) são aglomerações de empresas de pequeno e médio porte capazes de gerar um conjunto de benefícios aos produtores, exercendo um papel importante para o aumento da competitividade (SUZIGAN et al., 2003). Tais vantagens competitivas são, basicamente, de duas naturezas: primeiro, em virtude do processo de divisão do trabalho e da especialização dos produtores verificados nas aglomerações e, segundo, a concentração geográfica é capaz de proporcionar economias externas à firma, sendo estas apropriadas pelo conjunto dos produtores, mesmo que de forma assimétrica (SUZIGAN et al., 2001).

Gonçalves et al. (2012, p. 833), ao analisarem as definições apresentadas na literatura, descreveram os APLs como: 
concentrações territoriais e setoriais de agentes econômicos, políticos e sociais em torno de uma atividade econômica específica, nas quais se estruturam vínculos e relações de interação, interdependência, cooperação e aprendizagem, voltadas para o enraizamento da capacitação inovativa contínua, essencial para geração de competitividade e sustentabilidade dos seus membros, como também para a promoção do dinamismo econômico local da região em que o APL está inserido, diminuindo as disparidades intra e inter-regionais (GONÇALVES et al, 2012, p. 833).

A cooperação entre as empresas e destas com outros agentes é o elemento essencial para o desenvolvimento das pequenas empresas presentes nos APLs, o que foi mostrado inclusive estatisticamente no pólo calçadista do Vale dos Sinos (SCHMITZ, 1998; SUZIGAN et al., 2003).

O setor calçadista nacional é formado aproximadamente por 7,9 mil empresas que geram 303 mil empregos diretos, apresentando capacidade instalada em 804 milhões de pares por ano, sendo que 166 milhões foram destinados à exportação em 2008 (ABICALÇADOS, 2011).

Mesmo tendo o Estado do Rio Grande do Sul a maior concentração de empresas, considerado, portanto, o berço do calçado no Brasil, a produção brasileira está sendo gradualmente distribuída para outros polos, como no interior do Estado de São Paulo (Jaú, Franca e Birigui), bem como para Estados como a Paraíba, Ceará, Bahia e Santa Catarina.

O pólo calçadista de Jaú é formalmente reconhecido como um APL pelos órgãos governamentais, ao possuir aproximadamente 250 empresas fabricantes de calçados, representando mais de $40 \%$ do PIB municipal. Isso o faz responsável por 10.000 empregos (dos quais 6.000 diretos e 4.000 indiretos), possuindo capacidade instalada para produzir mais de 100.000 pares de calçados/dia, sendo estes basicamente calçados femininos, que em sua grande maioria são de couro (SINDICALÇADOS, 2011).

O segmento coureiro-calçadista brasileiro, inclusive o APL de Jaú, observou um declínio de sua competitividade nos últimos anos, em virtude das mudanças tecnológicas, a abertura econômica e principalmente pela concorrência asiática. Apesar da maior parte da produção de calçados nacional estar concentrada nas grandes companhias (Vulcabrás/Azaléia, Alpargatas, Paquetá, etc), a característica 
do setor é ser composto de pequenas e médias empresas, que entram e saem facilmente do mercado e que utilizam ultrapassadas ferramentas de gestão.

Quanto à mentalidade enxuta em empresas calçadista, destaca-se o trabalho de Gati-Wechsler e Torres Junior (2008), que avaliaram a influência dos conceitos Lean no processo de inovação do produto, além do estudo de Yoshino (2008), autor que pesquisou 10 empresas nacionais e concluiu que poucas delas adotaram estratégias de Produção Enxuta, principalmente pela falta de mão de obra capacitada, cultura organizacional, ausência de conhecimento sobre lean, etc. Entretanto, sugeriu-se que a organização em clusters nos pólos industriais facilita o acesso às informações e ao conhecimento sobre as novas tecnologias de gestão, com a cooperação dos sindicatos, do poder público local e das indústrias.

De modo a contribuir com essa discussão, o presente estudo buscou identificar e analisar as práticas de produção do APL Calçadista de Jaú, especificamente quanto à existência de semelhanças na gestão do processo produtivo, aos desafios referentes à implementação de conceitos e ferramentas da Produção Enxuta, bem como às oportunidades de utilização de alguns desses conceitos e ferramentas.

\section{PROCEDIMENTO DE PESQUISA}

A literatura apresenta diversas estratégias para a realização de uma pesquisa, cada uma trazendo diferentes enfoques para a coleta e análise dos dados. O que diferencia a estratégia a ser utilizada está relacionado à questão de pesquisa proposta, ao controle que o pesquisador apresenta sobre eventos comportamentais atuais e ao grau de enfoque em acontecimentos contemporâneos, em oposição aos acontecimentos históricos (YIN, 2005).

Segundo Yin (2005), um estudo de caso tem o propósito de obter uma compreensão dos valores e práticas compartilhados por um determinado grupo, assim como utilizar ferramentas e métodos múltiplos para a coleta de dados. Além disso, esses métodos permitem investigações exploratórias em que as variáveis são ainda desconhecidas e o fenômeno ainda não é totalmente compreendido. Dessa 
forma, esse método de pesquisa foi selecionado por ser considerado o mais adequado para o desenvolvimento desse trabalho, além de ser o tipo de pesquisa mais utilizado nos estudos com empresas brasileiras para avaliar o grau de implantação da Produção Enxuta (WALTER; TUBINO, 2012).

Com base nas recomendações de Miguel (2007), Voss, Tsikriktsis e Frohlich (2002) e Yin (2005), o desenvolvimento da presente pesquisa compreendeu as fases de fundamentação teórica, seleção dos casos, coleta e análise de dados.

A fundamentação teórica, obtida por meio da revisão bibliográfica, possibilitou a identificação dos elementos da Produção Enxuta que são passíveis de serem observados e analisados. Os elementos nos quais essa pesquisa se baseou são apresentados no Quadro 1.

Quadro 1- Conceitos e ferramentas da Produção Enxuta analisados no APL Calçadista de Jaú

\begin{tabular}{|l|l|}
\hline \multicolumn{2}{|c|}{ Conceitos e ferramentas da Produção Enxuta } \\
\hline 1. & Produção Puxada e Fluxo Contínuo \\
\hline 2. & Integração da Cadeia de Fornecedores \\
\hline 3. & Operaçães Padronizadas \\
\hline $\mathbf{4}$. & Nivelamento da Produção \\
\hline $\mathbf{5 .}$ & Balanceamento da Produção \\
\hline $\mathbf{6 .}$ & Flexibilização da Mão de obra \\
\hline $\mathbf{7 .}$ & TQM \\
\hline $\mathbf{8 .}$ & TPM \\
\hline $\mathbf{9 .}$ & Troca Rápida de Ferramentas \\
\hline 10. & Gestão Visual \\
\hline 11. & Melhoria Contínua (Kaizen) \\
\hline 12. & Mapeamento do Fluxo de Valor (MFV) \\
\hline
\end{tabular}

Fonte: Anand e Kodali (2009); Mackelprang e Nair (2010); Pettersen (2009); Womack et al. (2004).

Foram realizados três estudos de casos em empresas pertencentes ao APL de Jaú. Para a coleta de dados foi utilizado o questionário de Gambi e Carpinetti (2010), aplicado no APL metal-mecânico da cidade de Sertãozinho. Este questionário foi dividido em seis tópicos, contendo perguntas sobre: informações gerais da empresa, planejamento da produção, pessoas, Produção Enxuta, fornecedores e gestão visual. 
A coleta dos dados ocorreu por meio de entrevistas semiestruturadas com os responsáveis pela área de produção e planejamento das empresas. Foram também realizadas visitas ao chão de fábrica, permitindo que as impressões e observações do pesquisador fossem, por sua vez, consideradas.

A análise dos dados ocorreu por meio da síntese de dados cruzados, que consistiu em tratar cada caso como um estudo separado, e na sequência obter conclusões mediante a análise dos dados únicos de forma cruzada.

\section{RESULTADOS}

As etapas envolvidas no processo produtivo da empresa são comuns em qualquer empresa calçadista: Corte, Pré-Pesponto, Pesponto, Pré-Montagem, Montagem e Acabamento, conforme ilustrado na Figura 1.

Figura 1 - Etapas gerais de um processo de fabricação de calçados

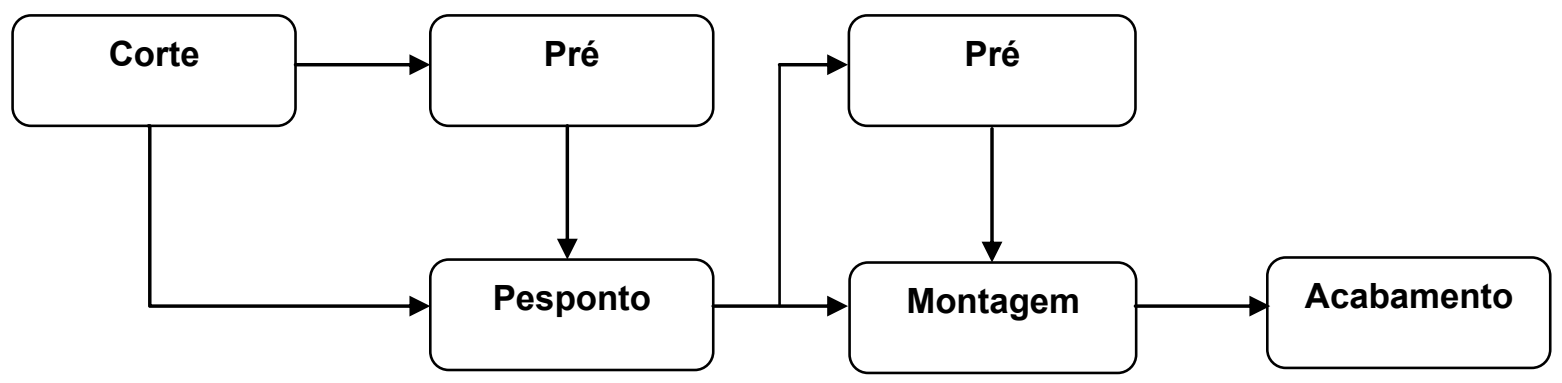

Basicamente todo calçado passa por estes processos, variando o tempo em cada etapa, layout das máquinas e processo.

- Corte: etapa referente ao corte da matéria-prima que formará o cabedal (parte superior do calçado) e o solado. O corte pode ser manual, utilizando-se facas e moldes de cartolina, por meio de uma prensa hidráulica, chamada de balancim de corte, ou pelo processo de CAD/CAM, em que um computador é acoplado a um equipamento de corte a laser, jato de água ou com micro serras;

- Pesponto: nessa etapa, as partes do cabedal são unidas pela costura com a ajuda das máquinas. Essa etapa é segmentada por operações de pré-Pesponto, de acordo com as características do calçado (chanfração, picotagem, dobra e colagem); 
- Pré-Montagem: as atividades que nessa etapa se realizam são a fabricação de solas, saltos e demais peças que comporão o calçado. $O$ solado é produzido paralelamente ao corte e a costura do cabedal, pois envolve o manuseio de vários tipos de materiais como: resinas, borrachas, plásticos, madeira e couro (FENSTERSEIFER, 1995).

- Montagem: etapa na qual o calçado passa a ter a forma de sapato. O cabedal é montado em uma forma plástica que tem a forma de um pé. Esta etapa da produção envolve outras atividades específicas como: preparação da palmilha, montagem do bico do sapato (principalmente o feminino), fechamento do calçados e montagem da traseira (YOSHINO, 2008).

- Acabamento: essa etapa envolve as operações de escovação, limpeza, eliminação de excesso de produtos e embalagem do calçado.

Os estudos de caso foram realizados em três empresas pertencentes ao APL de Jaú. O Quadro 2 apresenta de forma resumida, a caracterização das empresas estudadas.

Quadro 2 - Caracterização das empresas estudadas

\begin{tabular}{|l|c|c|c|}
\hline \multicolumn{1}{|c|}{ Empresa } & A & B & C \\
\hline Porte da empresa & Médio & Médio & Pequeno \\
\hline Consumidores (classe econômica) & A e B & B e C & C \\
\hline Produção (pares de calçado/dia) & 1000 & 1100 & 1000 \\
\hline
\end{tabular}

\subsection{Apresentação dos dados da empresa $A$}

Na empresa A, foi entrevistado o gerente de produção que é também responsável pelo desenvolvimento do produto e planejamento do processo produtivo da empresa. A empresa é de médio porte, e se destina a vender calçados femininos em couro, direcionados para as classes econômicas A e B, produzindo 1.000 pares diariamente. Os produtos são fabricados mediante pedido confirmado do cliente, que 
foi elaborado pelo departamento de desenvolvimento de coleção e modelagem, com base nas tendências da moda e quanto às modificações sugeridas pelo cliente.

O planejamento é realizado pelo Departamento de Planejamento e Controle de Produção (PCP), que por meio do software ERP, elabora as ordens de produção, dispara os pedidos de compra de matéria-prima e encaminha o planejamento para o gerente da fábrica.

O gerente realiza reuniões semanais com os líderes dos setores de produção, em que os comunicam a programação da semana seguinte e a meta a ser cumprida. Os líderes, após a reunião e de posse de documentos impressos, comunicam aos demais funcionários.

Segundo o entrevistado, existe um cronograma de manutenção periódica, porém, como todo equipamento é dedicado ao processo, quando há quebra, a produção é comprometida.

A empresa busca o nivelamento da produção com pouca variação no lead time, por meio da alocação programada dos pedidos feitos pelos representantes. Entretanto, como o tempo médio de entrega das matérias-primas pelos fornecedores varia entre 10 e 25 dias, ainda não é possível balancear completamente a produção.

Os funcionários obtêm treinamentos esporádicos: os que atuam na área de chão de fábrica recebem capacitação sobre determinadas tarefas do dia-a-dia, já os líderes, sobre modelos de gestão.

A empresa dispõe de conhecimento da Produção Enxuta, pois o gerente é mestrando em Engenharia de Produção e tem buscado trazer para dentro da fábrica essas técnicas e conceitos. Todavia, os maiores desafios são o treinamento e o conhecimento das ferramentas por parte da liderança, e principalmente pelos donos da empresa.

O entrevistado afirmou que utiliza algumas técnicas da Produção Enxuta como 5S, Poka Yoke, trabalho padronizado e funcionários multifuncionais, mas que para a empresa, no momento, a ferramenta mais importante a ser aplicada é o Mapa de Fluxo de Valor (MFV), pois conseguirá detectar desperdícios e o volume de estoques. 
O controle de qualidade é realizado por meio de amostragem, visualmente na linha de produção e por teste de calce, que consiste em solicitar a uma das funcionárias, que segundo a empresa tem o pé padrão de calce, coloque aleatoriamente alguns calçados acabados e relate se há alguma imperfeição.

O desempenho da empresa é avaliado por meio do mapa de competência, do perfil do colaborador, assim como pelo comparativo de produção e devolução. Todavia, todas as informações são colocadas na sala da gerência de produção e nos relatórios para a diretoria, não existindo, portanto, gestão visual.

\subsection{Apresentação dos dados da empresa B}

A empresa B apresenta um alto mix de produção, com ciclo de vida do produto de 2 a 3 meses e capacidade produtiva de 1100 pares/dia. Seu público alvo são mulheres das classes econômicas B e C, e seus produtos confeccionados em couro e distribuídos no mercado interno, em especial no Estado de São Paulo $(95 \%)$.

O responsável para responder a pesquisa foi 0 encarregado pelo Planejamento e Controle da Produção da empresa. O processo de produção é similar à empresa $\mathrm{A}$, desde o desenvolvimento do modelo, aprovação/adaptação pelo cliente e manufatura do calçado. O planejamento da produção é realizado via software ERP, específico para o setor, de forma que a programação é comunicada ao gerente e depois aos encarregados dos setores, com horizonte de programação semanal e diária.

Para a realização da produção, o processo é iniciado pela emissão de pedidos de produção "em lotes" que percorrem os processos, descrevendo o pedido do cliente quanto à numeração, cores e modelos. Toda a produção é empurrada de um setor para outro, e não existe um controle sobre em qual estágio do processo fabril os pedidos de produção dentro dos setores se encontram, além do grande número de matéria-prima em processo, o que acarreta em um alto lead time. Acrescenta-se ainda a política de não parar a produção para corrigir os desvios de 
programação, impactando na concentração de pedidos "quase prontos", porém, com algum tipo de problema no final da linha de produção.

Outro fator que prejudica a produção são os fornecedores de matéria-prima (metais e aviamentos) que, apesar de estarem no mesmo município e fazerem entregas diárias de produtos, não conseguem obedecer ao sequenciamento préestabelecido para o atendimento dos pedidos de produção.

Os equipamentos são dedicados a cada processo de fabricação dos calçados, não sendo utilizados nas demais etapas, uma vez que a sua manutenção é realizada periodicamente, conforme estabelecido pelo fornecedor do equipamento.

O gestor encarregado pelo PCP possui algum conhecimento sobre Produção Enxuta, adquirido pelas palestras realizadas em faculdades e pelo sindicato das empresas de calçados, com destaque para as abordagens 5S, melhoria do arranjo físico, TPM, Gestão Visual, SMED e padronização do trabalho. Recentemente foi aplicada na fábrica o Mapeamento do Fluxo de Valor (MFV), em que se estimou para uma família de produtos, um takt time de 28,8 segundos, lead time de produção de 33,8 dias e tempo de agregação de valor de 115 segundos. Identificou-se o Pesponto como etapa processo com um gargalo de 30 segundos de tempo de ciclo para cada par de calçado, e maior nível de estoque (9,57 dias).

Uma questão que chama a atenção é o desperdício, sendo um dos poucos indicadores de desempenho monitorados pela fábrica, ao ser apresentado por um alto índice de refugo de produtos que aparecem ao longo do processo de fabricação, Porém, sempre no final de cada setor, os setores mais críticos são o de Pesponto e de Montagem.

\subsection{Apresentação dos dados da empresa C}

Na empresa C, o respondente foi um dos proprietários, com a participação do encarregado pelo PCP. A empresa é caracterizada por ser de pequeno porte, atualmente administrada pelos filhos que herdaram dos pais os conhecimentos sobre o mercado de calçado. A empresa produz calçados com material sintético, 
direcionados para a classe econômica C, um diferencial em relação a grande maioria das empresas do APL, que produzem em couro bovino.

O processo de produção se inicia com a modelagem do calçado (nesta empresa ainda não há um departamento de desenvolvimento de modelos), ficando a cargo do modelista a busca por modelos em fontes de terceiros (revistas especializadas, viagens comerciais, feiras, etc) que, após as modificações sugeridas e de posse do pedido do cliente, encaminha-se para o PCP programar a produção e solicitar a compra da matéria-prima.

Não há um plano de treinamento, e as reuniões entre chefia e colaboradores são esporádicas. Não existe também nenhum acompanhamento da produção por meio de indicadores, sendo que as formas mais comuns de desperdícios são as devoluções dos clientes, refugos, tempo de espera e retrabalho e a grande quantidade de estoque em processo.

O responsável pelo PCP tem conhecimento sobre as técnicas de Produção Enxuta, adquiridos em treinamento e na graduação, mas ainda não conseguiu implantar nenhuma ferramenta, focando sua atenção no controle de refugo e na manutenção das máquinas.

Não há gestão visual na fábrica, de maneira que as informações são simplesmente colocadas no mural de entrada dos funcionários.

\subsection{Discussão dos Resultados}

Por meio do levantamento de campo, foi possível caracterizar o modo de produção das empresas. De modo geral, as empresas entendem que são flexíveis por serem de pequeno porte e atenderem às exigências do mercado da moda, impondo este as constantes alterações nos modelos (alto mix) e baixo volume de produção, típico dos calçados femininos. A administração das empresas B e C é tipicamente familiar, em que as funções dos gestores se confundem com a do próprio dono.

As três empresas pesquisadas possuem basicamente o mesmo processo de produção: corte, pré-Pesponto, Pesponto, pré-Montagem, Montagem do calçado e 
expedição. Elas desenvolvem seus produtos e realizam modificações conforme solicitação do mercado, sendo que a produção é disparada somente quando recebem o pedido firme do cliente. Em geral, os funcionários são especializados, mas não possuem plano formal de treinamento, e raramente são formados enquanto colaboradores multifuncionais, apesar da possibilidade da padronização dos processos produtivos e do trabalho dos operadores.

A manutenção dos equipamentos fica a cargo do responsável pela manutenção, que realiza consertos pontuais ou programa a manutenção periódica.

Os tipos de desperdícios mais comuns são a formação de estoque em processo, espera na linha, retrabalho e formação de estoques de produto acabado, em que o produto fica na expedição esperando que todo o lote seja produzido. Neste último caso, as causas são normalmente a falta de itens de produção (normalmente enfeites), retrabalho ou falha na programação. Como não há um programa de classificação ou formalização de parceria com fornecedores, e no desejo de se evitar a renegociação de prazos com os clientes, a alternativa normalmente é a de acumular estoques de matérias-primas.

Em geral, as empresas pesquisadas ainda precisam melhorar o seu fluxo de informação, seja na definição de objetivos e metas, na criação ou melhoria dos indicadores de desempenho, nas informações com o chão da fábrica e nos controles visuais na gestão.

As empresas pesquisadas estão cientes da importância de novas formas de gestão da produção, pois há uma percepção de que o sistema adotado até o momento atende às necessidades básicas de gestão, mas não garantirá a competitividade da empresa em um futuro próximo.

Entretanto, alguns desafios para a aplicação dos conceitos e das ferramentas da Produção Enxuta foram identificados na pesquisa:

a) As empresas entendem sobre a necessidade de mudanças em seus paradigmas de produção, pois o mercado tem exigido um ciclo de produção mais curto e com preços competitivos, mas compartilham a ideia de que a filosofia de Produção Enxuta é puramente aplicável no setor automobilístico, e ainda precisa de algumas adaptações para o setor 
calçadista;

b) Há dificuldade em se calcular o takt time e nivelar a produção, pois para atender ao mercado, as empresas são obrigadas a produzirem muitos tipos de calçados com pouca quantidade de cada modelo;

c) As empresas não possuem um programa ou se utilizam de ferramentas de qualidade e, mediante a constatação da ocorrência de algum tipo de controle, o mesmo é realizado no final da produção, resultando em retrabalho ou ajustes;

d) Há dificuldades de manutenção da força de trabalho visando à melhoria de suas qualificações (treinamento e formação de operadores multifuncionais), devido à grande rotatividade da mão de obra;

e) Inexistência de um modelo eficaz de fluxo de informações e de materiais na fábrica. Normalmente as informações são enviadas via software ERP, mas acabam não sendo recebidas pelo chão de fábrica;

f) Ainda não possuem um grupo de pessoas que são qualificadas para desenvolver iniciativas da Produção Enxuta.

Apesar dos desafios identificados, além da baixa utilização dos conceitos e técnicas da Produção Enxuta, entende-se que é possível aplicar essa filosofia nas empresas pesquisadas, resultando principalmente na eliminação de desperdícios, melhoria na lucratividade e ganhos de mercado. Assim, algumas sugestões são passíveis de serem aplicadas, conforme apresentado no Quadro 3. 
Quadro 3 - Sugestões de melhorias nas empresas pesquisadas

\begin{tabular}{|l|l|}
\hline \multicolumn{1}{|c|}{ Sugestão de melhoria } & \multicolumn{1}{c|}{ Objetivo } \\
\hline $\begin{array}{l}\text { Melhor entendimento, por parte dos } \\
\text { gestores e proprietários, das } \\
\text { empresas, dos conceitos e da } \\
\text { filosofia da Produção Enxuta }\end{array}$ & $\begin{array}{l}\text { Melhorar a compreensão e envolvimento dos gestores da } \\
\text { empresa. Os proprietários deverão ser os patrocinadores do } \\
\text { modelo e entender claramente quais os benefícios e desafios } \\
\text { desta implantação. }\end{array}$ \\
\hline Realização de eventos kaizen & $\begin{array}{l}\text { Treinamentos, reuniões e ações de melhoria, possibilitam a } \\
\text { disseminação da mentalidade de combate ao desperdício. }\end{array}$ \\
\hline Treinamento para funcionários & $\begin{array}{l}\text { Tornar os funcionários multifuncionais, melhorando a } \\
\text { flexibilidade do sistema produtivo das empresas. }\end{array}$ \\
\hline $\begin{array}{l}\text { Aumento do fluxo de informações } \\
\text { entre o planejamento e o chão de } \\
\text { fábrica e entre as áreas da empresa }\end{array}$ & $\begin{array}{l}\text { Melhorar o fluxo contínuo, por meio da redução do número } \\
\text { de paradas na linha de produção e retrabalho. Tais melhorias } \\
\text { podem ser alcançadas por meio de ferramentas como 5S e } \\
\text { gestão visual. }\end{array}$ \\
\hline $\begin{array}{l}\text { Nivelamento da produção de acordo } \\
\text { com a demanda }\end{array}$ & $\begin{array}{l}\text { Reduzir os custos com o pagamento de horas extras e o } \\
\text { tempo ocioso em alguns períodos do ano. }\end{array}$ \\
\hline $\begin{array}{l}\text { Elaboração e cumprimento de } \\
\text { planos de manutenção preventiva } \\
\text { para os equipamentos }\end{array}$ & $\begin{array}{l}\text { Reduzir o número de interrupç̃̃es inesperadas no fluxo } \\
\text { produtivo por quebra ou mau funcionamento de } \\
\text { equipamentos. }\end{array}$ \\
\hline $\begin{array}{l}\text { Desenvolvimento de iniciativas de } \\
\text { programas da qualidade }\end{array}$ & $\begin{array}{l}\text { Reduzir retrabalho, refugos da produção e reclamações de } \\
\text { clientes. }\end{array}$ \\
\hline $\begin{array}{l}\text { Formação de parcerias com } \\
\text { fornecedores }\end{array}$ & $\begin{array}{l}\text { Reduzir atrasos na entrega da matéria-prima, do produto } \\
\text { acabado (cumprimento ao prazo de entrega), reduzir } \\
\text { formação de estoques e descapitalização da empresa } \\
\text { (capital de giro). }\end{array}$ \\
\hline
\end{tabular}

\section{CONSIDERAÇÕES FINAIS}

Esse trabalho teve por objetivo conhecer a realidade das empresas calçadistas do APL de Jaú, visando identificar semelhanças no processo de produção, implementação dos conceitos e ferramentas da Produção Enxuta, bem como a oportunidade de utilização desses conceitos e técnicas.

A pesquisa permitiu identificar diversas oportunidades de melhoria que essas empresas podem obter com a implementação de conceitos e ferramentas de Produção Enxuta. Para isso, alguns conceitos de produção tradicionalmente utilizados, tais como o acúmulo de estoques de matéria-prima, o sistema empurrado 
e a especialização da mão de obra deverão ser abandonados, visando uma evolução em seus sistemas de produção.

Os resultados demonstraram que as empresas estudadas dispõem de pouco conhecimento sobre os conceitos e ferramentas da Produção Enxuta, e ainda desconhecem os benefícios que a aplicação destes pode proporcionar. Sugere-se a implementação de conceitos simples como 5S e Mapeamento do Fluxo de Valor (MFV), pois devem disseminar os conceitos e técnicas para todo o ambiente produtivo calçadista.

Além disso, o aprendizado com a implantação dessas ferramentas permitirá a construção de uma base para futuras melhorias, devendo ainda adicionar competitividade às empresas, principalmente com o aumento da capacidade de produção instalada, redução de lead time, diminuição dos índices de retrabalho, refugo e devoluções e redução de prazo de entrega aos clientes, o que seria um diferencial em relação à concorrência.

Por fim, destaca-se a contribuição deste trabalho no sentido de que são discutidas as formas de gestão de produção para as Pequenas e Médias Empresas (PMEs), pois àquelas que desejam implantar alguns destes conceitos, deverão adaptar-se as novas exigências do mercado globalizado.

Como propostas futuras, sugere-se a realização de estudos que possam colocar em prática as sugestões propostas neste trabalho, e que também sejam proporcionadas mudanças na cultura empresarial do APL, que ainda se vale de práticas de gestão que focam basicamente os resultados de curto prazo.

\section{REFERÊNCIAS}

ABICALÇADOS - ASSOCIAÇÃO BRASILEIRA DAS INDÚSTRIAS DE CALÇADOS. Resenha estatística. Disponível em: <www.abicalcados.com.br $>$. Acesso em: 15 fev. 2011.

ANAND, G.; KODALI, R. Selection of lean manufacturing systems using the analytic network process - a case study. Journal of Manufacturing Technology

Management. v. 20, n. 2, p. 258-289, 2009. 
ANTONY, J. Six Sigma vs Lean: some perspectives from leading academics and practitioners. International Journal of Productivity and Performance Management, v. 60, n. 2, p. 185-190, 2011.

BACHEGA, S. J.; GODINHO FILHO, M. Identificação de foco estratégico e de consistências entre fins e meios em empresas calçadista do Estado de São Paulo. Gestão \& Produção, São Carlos, v. 18, n. 2, p. 391-408, 2011.

DEMETER, K.; MATYUSZ, Z. The impact of lean practices on inventory turnover. International Journal of Production Economics, v. 133, p. 154-163, 2011.

DIGALWAR, A. K.; SANGWAN, K. S. Development and validation of performance measures for world class manufacturing practices in India. Journal of Advanced Manufacturing Systems. V. 6, n. 1, p. 21-38, 2007.

FENSTERSEIFER, J. E. O Complexo calçadista em perspectiva: tecnologia e competitividade: estudos sobre a competitividade da indústria calçadista sob a ótica da tecnologia. Ortiz, 1995.

FUJIMOTO, T.; TIDD, J. The UK \& Japanese automobile industries: adoption \& adaptation of Fordism. University of Tokio, Japan, 1984.

FULLERTON, R. R.; MCWATTERS, C. S. The production performance benefits from JIT implementation. Journal of Operations Management. v. 19, p. 81-86, 2001.

HALLGREN, M.; OLHAGER, J. Lean and agile manufacturing: external and internal drivers and performance outcomes. International Journal of Operations \& Production Management, v. 29, n. 10, p. 976-999, 2009.

GAMBI, L. N.; CARPINETTI, L. C. R. Aplicabilidade de conceitos e técnicas do sistema de produção enxuta em empresas fabricantes do aglomerado de Sertãozinho. In: ENCONTRO NACIONAL DE ENGENHARIA DE PRODUÇÃO, 2010. São Carlos. Anais... São Carlos: ABEPRO, 2010.

GATI-WECHSLER, A. M.; TORRES JUNIOR, A. S. The influence of lean concepts on the product innovation process of a Brazilian shoe manufacturer. Proceeding of the PICMET, South Africa, 2008.

GONÇALVES, A. T. P.; LEITE, M. S. A.; SILVA, R. M. Um estudo preliminar sobre as definições e as diferenças dos principais tipos de arranjos empresariais. Revista Produção Online, v. 12, n. 3, p. 827-854, 2012.

HOLWEG, M. The genealogy of lean production. Journal of Operations Management, v. 25, p.420-437, 2007. 
HOUNSHELL, D. A. From the american system to mass production 1800-1932: the development of manufacturing technology in the U.S. Baltimore: Johns Hopkins University Press, 1984.

HOBSBAWN, E. A era dos extremos: o breve século XX - 1914-1991. 2. ed. São Paulo: Companhia das Letras, 2003.

HOFER, C.; EROGLU, C.; HOFER, A. R. The effect of lean production on financial performance: the mediating role of inventory leanness. International Journal of Production Economics, v.138, p. 242-253, 2012.

KAYNAK, $\mathrm{H}$. The relationship between total quality management practices and their effects on firm performance. Journal of Operations Management, v. 21, p. 405435, 2003.

LIKER, J. K. O Modelo toyota: os 14 princípios de gestão da maior fabricante do mundo. Porto Alegre: Bookman, 2005.

LIN, C; CHANG, S. Exploring TQM's impact on the causal linkage between manufacturing objective and organizational performance. Total Quality Management, v. 17, n. 4, p. 465-484, 2006.

MACKELPRANG, A. W.; NAIR, A. Relationship between just-in-time manufacturing practices and performance: A meta-analytic investigation. Journal of Operations Management, v. 28, p. 283-302, 2010.

MIGUEL, P. A. C. Estudo de caso na engenharia de produção: estruturação e recomendações para sua condução. Produção, v. 17, n. 1, p. 216-229, 2007.

NOGUEIRA, M. G. S.; SAURIN, T.A. Proposta de avaliação do nível de implementação de típicas práticas da produção enxuta em uma empresa do setor metal-mecânico. Revista Produção Online, v. 08, n. 2, 2008.

PETTERSEN, J. Defining lean production: some conceptual and practical issues. The TQM Journal. v. 21, n. 2, p. 127-142, 2009.

RAHMAN, S.; LAOSIRIHONGTHONG, T.; SOHAL, A. S. Impact of lean strategy on operational performance: a study of thai manufacturing companies. Journal of Manufacturing Technology Management, v. 21, n. 7, p. 839-852, 2010.

RENTES, A. F.; SILVA, A. L.; SILVA, V. C.; CASTRO, S. A. Aplicando os conceitos de lean production em uma indústria de calçados: um estudo de caso. In: SIMPÓSIO NACIONAL DE ENGENHARIA DA PRODUÇÃO (SIMPEP), 10,. 2003, Bauru.

Anais... Bauru: UNESP, 2003.

ROTHER, M.; SHOOK, J. Aprendendo a enxergar: mapeando o fluxo de valor para agregar valor e eliminar desperdício. Lean Enterprise Institute do Brasil, 2003. 
SALGADO, E. G. et al. A. Análise da aplicação do mapeamento do fluxo de valor na identificação de desperdícios do processo de desenvolvimento de produtos. Gestão \& Produção, v. 16, n. 3, p. 344-356, 2009.

SAURIN, T. A.; RIBEIRO, J. L. D.; MARODIN, G. A. Identificação de oportunidades de pesquisa a partir de um levantamento da implantação da produção enxuta em empresas do Brasil e do exterior. Gestão \& Produção, v. 17, n. 4, p. 829-841, 2010.

SAURIN, T. A.; MARODIN, G. A.; RIBEIRO, J. L. D. A framework for assessing the use of lean production practices in manufacturing cells. International Journal of Production Research, v. 49, n. 11, p. 3211-3230, 2011.

SCHMITZ, H. Responding to global competitive pressure: local co-operation and upgrading in the Sinos Valley, Brazil. Brighton: Institute of Development Studies. IDS Working Paper, 82, 58p, 1998.

SHAH, R.; WARD, P. Lean manufacturing: context, practice bundles, and performance. Journal of Operations Management, v. 21, p. 129-149, 2003.

SHINGO, S. O Sistema toyota de produção do ponto de vista da engenharia de produção. 2. ed. Porto Alegre: Artes Médicas, 1996.

SILVA, V. C. O.; RENTES, A. F. A importância da produção enxuta nas empresas brasileiras do setor agroindustrial. In: ENCONTRO NACIONAL DE ENGENHARIA DE PRODUÇÃO (ENEGEP), 24,. 2004. Florianópolis. Anais... Santa Catarina: UFSC: ABEPRO, 2004.

SINDICALÇADOS DE JAÚ. Caracterização do APL de calçados femininos de jaú. APL. Disponível em: <www.sindicaljau.com.br> . Acesso em: 15 fev. 2011.

SUZIGAN, W. et al. Coeficientes de gini locacionais - GL: aplicação à indústria de calçados do Estado de São Paulo. Nova Economia, v. 13, n. 2, p. 395, 2003. $\overline{5, \text { n. 4, } 2001 .}$

. Aglomerações industriais no Estado de São Paulo. Economia Aplicada, v.

THOMAS, A.; et al. Identifying the characteristics for achieving sustainable manufacturing companies. Journal of Manufacturing Technology Management, v. 23, n. 4, p. 426-440, 2012.

VOSS, C.; TSIKRIKTSIS, N.; FROHLICH, M. Case research in operations management. International Journal of Operations \& Production Management, v.22, n.2, p.195-219, 2002. 
WALTER, O. M. F. C.; TUBINO, D. F. Avaliação da implantação da manufatura enxuta: uma análise dos anais do Enegep. Revista Produção Online, v. 12, n. 3, p. 604-628, 2012.

WOMACK, J. P.; JONES, D. T.; ROOS, D. A máquina que mudou o mundo. Rio de Janeiro: Elsevier, 2004.

WOMACK, J.; JONES, D. A mentalidade enxuta nas empresas: elimine o desperdício e crie riquezas. 5. ed. Rio de Janeiro: Campus, 2004.

YOSHINO, R. T. Proposta de um sistema de produção enxuta para o segmento calçadista. 315 f. Tese (Doutorado) - Escola de Engenharia de São Carlos, Universidade de São Paulo, São Carlos, 2008.

YIN, R. K. Estudo de caso: planejamento e métodos. São Paulo: Artmed Editora S.A, 212 p., 2005.

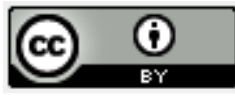

Artigo recebido em 30/07/2012 e aceito para publicação em 01/11/2012. 